\title{
MECANISMOS ELETRÔNICOS DE COMPRAS E DE EVIDENCIAÇÃO E O DESEMPENHO NA GESTÃO DE ESTOQUES PÚBLICOS: O CASO DOS ESTADOS BRASILEIROS
}

\author{
Paulo Sérgio Almeida-Santos¹, Patrícia Siqueira Varela², José Matias-Pereira ${ }^{3}$
}

\section{RESUMO}

Estudos apontam o superdimensionamento e o subdimensionamento dos estoques governamentais. Neste contexto, a gestão de estoques ainda preocupa as entidades públicas, apesar de inúmeras pesquisas já terem sugeridos diversos mecanismos para a gestão de materiais. A pesquisa quantitativa do tipo documental e descritiva, em que investiga o caso dos estados brasileiros, objetiva verificar se mecanismos eletrônicos de compras e mecanismos de evidenciação contribui para melhorar o desempenho na gestão dos estoques públicos. Os mecanismos eletrônicos de compras são definidos pela - existência ou não portal de compras e de sistema de registro de preços; os mecanismos de evidenciação são definidos pela - divulgação e detalhamento ou não da conta contábil estoques e, pelo fato da entidade possuir ou não um órgão de Controladoria e, também pelo nível de transparência estadual. $\mathrm{O}$ desempenho na gestão dos estoques é encontrado pelo cálculo do prazo médio de giro dos estoques. Os achados a priori indicam uma média de giro superior a seis meses; o teste de médias para duas amostras independentes sugerem que o portal de compras e o sistema de registro de preços não interferem na gestão dos estoques públicos. Do mesmo modo percebese que a evidenciação e o detalhamento da conta contábil, bem como o fato de a entidade possuir um órgão de Controladoria e apresentar um maior nível de transparência não proporcionam um melhoramento do desempenho na gestão dos estoques públicos estaduais.

Palavras-chave: Portal de compras. Sistema de registro de preços. Evidenciação. Estoques públicos.

\section{ELECTRONIC MECHANISMS OF PURCHASING AND DISCLOSURE AND PERFORMANCE IN INVENTORY MANAGEMENT PUBLIC: THE CASE OF BRAZILIAN STATES}

\begin{abstract}
Researches' indicate oversizing and the undersize of government stocks. In this context, the inventory management still concerned public authorities, despite numerous studies have already suggested several mechanisms for material management. Quantitative research documentary and descriptive, in investigating the case of the Brazilian states, aims to verify whether electronic mechanisms shopping and disclosure mechanisms helps to improve performance in managing public stocks. Electronic purchasing mechanisms are set by whether or not purchasing portal and price registration system; the disclosure mechanisms are set by - disclosure and detailing or not the accounting inventory account and the entity actually have or not a Controlling body and also by the level of state transparency. The performance in the management of stocks is found by calculating the average term of inventory turnover. The findings indicate a priori an average higher working six months; the mean test for two independent samples suggest that the shopping portal and the price registration system do not interfere in the management of public stocks. Similarly it realizes that the disclosure and details of the accounting account, as well as the fact that the entity has
\end{abstract}

\footnotetext{
${ }^{1}$ Universidade Brasília/Universidade Federal de Mato Grosso.

${ }^{2}$ Universidade de São Paulo

${ }^{3}$ Universidade de Brasília - PPGCONT
} 
an organ Comptroller and provide a higher level of transparency does not provide a performance improvement in the management of state public stocks.

Keywords: Shopping Portal. Price registration system. Disclosure. Public stocks.

\section{INTRODUÇÃO}

A gestão de estoques tem ganhado uma vultosa atenção nos meios acadêmicos e empresarial nos últimos anos (WANKE, 2005). Os principais pontos tratados pela literatura sobre estoques consistem, em estabelecer métodos para ressuprimento e distribuição dos estoques (BOTTER; FORTUIN, 2000).

No setor público a gestão de estoques tem sido um dos motivos de preocupação dos gestores, pois estes devem manter nos almoxarifados das entidades que administram a quantidade de materiais suficiente para atender a demanda de serviços a serem prestados à sociedade (ver: MOTA; CANCIO, 2004; WANKE, 2003, FREITAS et al., 2008; VIEIRA, 2008; CARVALHO, 2009; FREITAS; VIEIRA, 2009; SANTOS et al., 2009). Assim, tanto o superdimensionamento quanto o subdimensionamento de estoques geram prejuízos, bem como dão indícios de um controle ineficiente (TUNG, 2001).

O excesso de estoques pode gerar ineficiências provocadas por diversos fatores, por exemplo: (i) os gestores precisam recorrer a espaços físicos de terceiros para o armazenamento dos materiais, em função da falta de espaço nas entidades, o que provoca custos adicionais além daqueles já encontrados nos próprios almoxarifados da entidade; (ii) o desvio de materiais dos almoxarifados das entidades, pois quanto maior for o volume de estoques, mais eficiente tem que ser o seu controle; e (iii) deterioração e obsolescência dos itens estocados; e etc. A falta de estoques, por sua vez, pode trazer grandes prejuízos à população local, por exemplo, os mais comuns, a falta de merenda escolar e a falta de medicamentos.

Soluções para o descontrole dos estoques das entidades públicas brasileiras têm sido apresentadas. Por exemplo, a imposição de regras por meio do estabelecimento de leis $\left(\mathrm{n}^{\circ}\right.$ 8.666/93 e $\mathrm{n}^{\circ} 10.520 / 2002$ ) que têm como alcance tratar também a respeito da aquisição de materiais em âmbito público, bem como mecanismos eletrônicos mais sofisticados que buscam acelerar os processos de compras dos órgãos governamentais brasileiros. $\mathrm{O}$ desenvolvimento de portal de compras, e consequentemente aquisições por meio do sistema de registro de preços (SRP) proporciona, principalmente a economicidade de recursos públicos. Esse mecanismo é um dos fortes aliados dos princípios da eficiência e da economicidade, por estabelecer vantagens à administração pública, por exemplo, a desburocratização das aquisições, a redução do volume de estoques e, também quanto à 
otimização de recursos públicos (FERNANDES, 2008). A utilização do SRP possibilita a minimização dos estoques públicos e, por consequência a redução dos custos de armazenagem (CGU, 2011).

Mecanismos de evidenciação também pode sinalizar uma boa gestão de estoques pelas entidades públicas. A própria evidenciação e o detalhamento da conta contábil, pode sinalizar isto. A entidade ao divulgar, por exemplo, a conta contábil de estoques, de forma analítica, isto é, detalhando cada subgrupo da conta de estoques, informa em que item deste ativo, está aplicado a maior parte dos recursos. Bem como informar a política contábil adotada para mensuração dos estoques, pode transparecer que a entidade possui, um controle efetivo sobre eles. Informações detalhadas enfatizam a eficácia das políticas dos administradores (PACE et al., 2003). Segundo (Silva et al., 2007 apud CVM, 1987) a divulgação de informações de modo detalhado possibilita o conhecimento da entidade, de seus objetivos e políticas, trata-se de um direito essencial da parte interessada. A evidenciação de informações contábeis auxiliam os cidadãos, a obterem subsídios sobre a gestão governamental, destacando os resultados e o desempenho obtidos por ela (AVELINO et al., 2010).

Um órgão que pode auxiliar na preparação e divulgação das informações relacionadas aos estoques e, também no que tange ao seu controle, diz respeito à Controladoria. Uns dos atributos da Controladoria podem ser: o auxílio na minimização dos custos da entidade, criar e aperfeiçoar os controles internos da entidade, além de preparar e divulgar as informações necessárias para a tomada de decisão (OLIVEIRA et al., 2002). Um órgão de Controladoria pode auxiliar no fornecimento de informações favoráveis para tomada de decisão dos gestores públicos, além melhorar os controles operacionais e administrativos da entidade (BIACHI et al., 2006; SUZART et al., 2012).

Levando-se em consideração o que brevemente foi exposto, o propósito do artigo consiste em verificar, se mecanismos eletrônicos de compras e mecanismos de evidenciação contribuem para melhorar o desempenho na gestão dos estoques públicos. Os mecanismos eletrônicos de compras são definidos pela - existência ou não portal de compras e de sistema de registro de preços. Os mecanismos de evidenciação são definidos pela - divulgação e detalhamento ou não da conta contábil estoques e, pelo fato da entidade possuir ou não um órgão de Controladoria e, também pelo nível de transparência estadual. O desempenho na gestão dos estoques é encontrado pelo cálculo do prazo médio de giro dos estoques. Este objetivo é na tentativa de responder a dois questionamentos basicamente: $\mathrm{O}$ desempenho na gestão de estoques pode ser melhor em estados que possuem mecanismos eletrônicos de 
compras? O desempenho na gestão de estoques pode ser melhor em estados que fazem o uso de mecanismos de evidenciação?

Teoricamente o estudo contribui para literatura sobre a eficiência na gestão dos estoques públicos, em que defende a ideia que - o desempenho na gestão dos estoques públicos pode está relacionada positivamente com alguns mecanismos eletrônicos de compras e com alguns mecanismos de evidenciação. De modo prático, o estudo enseja a academia e aos gestores governamentais que - mecanismos eletrônicos conjugados a mecanismos de evidenciação podem ser úteis para o melhoramento da gestão dos estoques públicos. Socialmente, o estudo contribui salientando que - os estoques públicos precisam ser bem administrados, seus custos necessitam cada vez mais ser minimizados e, consequentemente havendo economicidade, os seus recursos possam ser revestidos em outras áreas de interesse da população local.

\section{GESTÃO DE ESTOQUES PÚBLICOS E MECANISMOS ELETRÔNICOS DE COMPRAS}

O objetivo primordial da gestão de estoques é não deixar faltar material, bem como evitar a sua alta imobilização (REIAS, 2007). Estudos anteriores já trataram da temática relacionada aos estoques públicos. Os principais enfoques foram: níveis de estoques, gestão de estoques e técnicas de gestão de estoques públicos, por exemplo, (ver: MOTA; CANCIO, 2004; WANKE, 2003, FREITAS et al., 2008; VIEIRA, 2008; CARVALHO, 2009; FREITAS; VIEIRA, 2009; SANTOS et al., 2009). As críticas destes trabalhos sinalizam a mesma situação: a má gestão dos estoques públicos. Muitos recursos financeiros são aplicados pelas entidades públicas em estoques, todavia, não existe uma preocupação dos gestores em relação aos seus controles; caso contrário poderia proporcionar economicidade dos recursos públicos (MOTA; CANCIO, 2004).

Para que haja uma boa gestão de estoques públicos deve haver eficiência nos mecanismos de: compras, acompanhamento, gestão de armazenagem, planejamento, controle relativos à produção ou prestação de serviços; e gestão na distribuição física (MOURA 2004). De acordo com Mota e Cancio (2004) a redução dos estoques públicos exige que haja uma mudança em tais mecanismos incluindo a postura de seus responsáveis.

Segundo Arozo (2006) o processo de gestão de estoques pode ser desarranjado em quatro itens basicamente: políticas e modelos quantitativos utilizados; questões organizacionais envolvidas; tecnologia utilizada; e monitoramento do desempenho do processo. No que se refere aos indicadores de desempenho utilizados na gestão de estoques, 
podem se segmentar, em três grupos: custo, serviço e conformidade do processo; o custo e o serviço "estão relacionados aos resultados do processo que compõem o trade-off básico da gestão de estoque, ou seja, o balanceamento do nível de estoque com o nível de serviço com o objetivo de obter-se o menor custo total"; a conformidade do processo associa-se as causas da consecução do desempenho ou eficiência na gestão dos estoques (AROZO, 2006, p. 1).

O principal problema apontado por Wanke (2005), diz respeito, às quais itens devem ser estocados e, o quanto de cada item pode permanecer em estoque. Esta dificuldade é central no setor público. A instabilidade de recursos financeiros e créditos orçamentários disponíveis pode ocasionar alto volume de estoques nos almoxarifados das entidades públicas; o grande vulto de materiais estocados também pode ser resultante dos riscos de atrasos nas entregas e oscilações na demanda (MOTA; CANCIO, 2004). Ainda de acordo com Mota e Cancio (2004), o demorado e burocrático processo de aquisição de materiais também contribuem para a formação de altos volumes de estoques dentro das entidades públicas. Deste modo, infere-se que tais fatores fazem com que os órgãos públicos estoquem "material ao final de cada exercício financeiro, além do necessário, visando prevenirem-se para a falta de estoques decorrentes de contratempos na aprovação do orçamento, na liberação de recursos financeiros ou nos procedimentos de licitação". (MOTA; CANCIO, 2004, p. 1).

Apesar de estes problemas, as entidades de modo geral, devem manter estoques baixos, almejando a redução de custos, contudo, não podem colocar em risco os níveis de serviços prestados (REIS, 2007). Um volume alto de estoques ou sua falta pode refletir negativamente no setor público (SALDANHA, 2006). De modo sugestivo, Santos et al. (2009) indicam que a deficiência na gestão dos estoques públicos poderiam ser minimizados se houvesse um sistema integrado (ERP), substancialmente haveria uma melhora do controle dos materiais adquiridos. Sistemas integrados auxiliam na minimização dos custos, além de proporcionar uma melhor produtividade e eficiência, facilitando ainda os registros de entradas e saídas dos almoxarifados das entidades públicas, prevenido, portanto, o excesso ou falta de materiais (MORESI, 2000).

Além das leis $n^{\circ} 8.666 / 93$ e $n^{\circ} 10.520 / 2002$, às quais gerenciam as compras de bens de serviços da administração pública. Mecanismos eletrônicos de compras podem auxiliar as entidades públicas na economicidade de recursos, especialmente, no que se referem gestão de estoques. A criação de um portal de compras pode fazer com que a entidade venha minimizar principalmente os seus custos de estocagem, pois enseja a utilização do mecanismo de sistemas de registro de preços. Este mecanismo permite a entidade sistematizar informações a 
respeito das vantagens e desvantagens de forma prática efetiva sobre suas futuras aquisições (CARVALHO, 2008).

Segundo a CGU (2011), o SRP consiste em um mecanismo com base no planejamento de diversos órgãos e entidades públicas para "futura contratação de bens e serviços, por meio de licitação na modalidade de concorrência ou pregão, em que as empresas vencedoras assumem o compromisso de fornecer bens e serviços a preços e prazos registrados em uma ata específica". Conforme Freitas et al. (2008), o SRP estabeleceu a possibilidade de entrega parcelada dos bens ou serviços licitados, durante um período máximo de um ano, e o compartilhamento dos preços registrados em processos licitatórios realizados pelos demais órgãos estaduais, por meio de adesão às Atas de Registro de Preços. Segundo Carvalho (2008, p. 37), com o SPR “a administração pode fazer diversos pedidos, em curto espaço de tempo e com rapidez, de um mesmo item", ganhando, portanto, celeridade e, consequentemente trabalhando com mais eficiência na prestação dos seus serviços.

Além do aspecto da eficiência e economicidade, o SRP pode favorecer a prestação de contas pelos gestores públicos, assim, como asseguram as normas e regulamentos que regem as licitações e contratos na administração pública. A correta utilização do SRP pode diminuir consideravelmente os níveis de estoques nos almoxarifados das entidades públicas, portanto, trata-se de um mecanismo eficiente para reduzir os custos e ganhar produtividade nos serviços a serem prestados (CARVALHO, 2008). O SRP desburocratiza as compras públicas, ampliando o poder de compra, proporcionando mais agilidade na hora de contratar com mais economia.

Os principais materiais que formam os estoques públicos são formados basicamente em sua maioria por material de consumo e material de distribuição gratuita.

Muitos destes materiais de estoques, ainda são agrupados em uma única contábil pelas entidades públicas brasileiras. Diante disto, especificamente sobre os estoques públicos, buscou-se realizar um paralelo entre as normas brasileiras (Lei $\mathrm{n}^{\circ}$ 4.320, NBC T 16 e Manuais da STN) e internacionais (IPSAS 12) que tratam do assunto, sobretudo, no que ser refere os seguintes aspectos: definição, detalhamento, critério de avaliação, mensuração, evidenciação e custos.

De modo global, percebe-se que as normas brasileiras pouco atende os principais aspectos relacionados aos estoques. Entretanto, considerando o contexto de transformação da contabilidade pública e, os estoques como um dos elementos patrimoniais que interferem diretamente na condução dos programas governamentais; entender as alterações no tratamento contábil dos estoques pelas normas brasileiras e internacionais é um passo importante para 
compreender os avanços que se esperam quanto à transparência e evidenciação das contas públicas. Este fator, por sua vez, pode favorecer a gestão eficiente dos gastos públicos. As normas internacionais de contabilidade aplicadas ao setor público consistem na peça central para a revolução global da contabilidade governamental, em que é dada maior responsabilização e transparência às finanças públicas (HEALD; 2003, apud CHAN, 2009).

É mister frisar que a STN, por meio de seus manuais têm dado ênfase ao detalhamento dos estoques, contudo, raríssimos ainda são os governos estaduais que divulgam informações relativas aos seus estoques de modo pormenorizada, porém, estando completo o processo de convergência da contabilidade pública brasileira às IPSAS; espera-se que a evidenciação das demonstrações contábeis das entidades públicas brasileiras, sejam mais completa, em que se incluem o - maior detalhamento da conta contábil estoques.

\subsection{MECANISMOS DE EVIDENCIAÇÃO}

A evidenciação é um aspecto central para a Contabilidade, podendo ser considerada como a abertura de informação, ou seja, a entidade por meio da divulgação de informações garante a transparência diante do público e, de outros interessados (GOULART, 2003). A evidenciação no setor público procura aumentar o máximo possível o nível de divulgação, bem como de transparência das informações junto aos cidadãos, diminuindo a assimetria informacional e, assim, assegurando uma maior confiança por parte da sociedade (MELLO, 2009). Além de diminuir a assimetria de informação, a evidenciação tem papel fundamental na comunicação entre os gestores das entidades e o público externo, além de permitir a verificação do desempenho da administração (LANZANA et al. 2006).

A Lei de Responsabilidade Fiscal (LRF) atualmente é um dos instrumentos mais importantes para assegurar a transparência das contas públicas e impor aos gestores a accountability em suas administrações, ela reza que: “[...] a responsabilidade na gestão fiscal pressupõe a ação planejada e transparente, em que se previnem riscos e corrigem desvios capazes de afetar o equilíbrio das contas públicas." Para isso, é prevista a ampla divulgação de diversos instrumentos de transparência da gestão fiscal, quais sejam: os planos, orçamentos e leis de diretrizes orçamentárias; as prestações de contas e o respectivo parecer prévio; o Relatório Resumido da Execução Orçamentária e o Relatório de Gestão Fiscal; e as versões

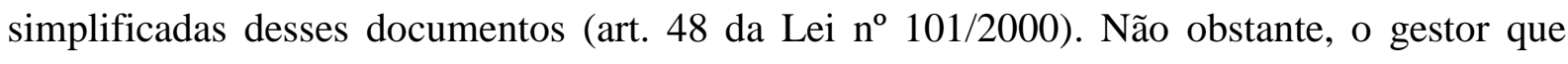
pretende demonstrar à sociedade o seu trabalho de forma eficiente terá que adotar algumas medidas ao prestar suas contas, além daquelas impostas pela legislação, para, assim, transmitir à sociedade segurança e/ou confiança em relação à sua gestão. 
A accountability é um conjunto de mecanismos e procedimentos por meio dos quais os gestores públicos prestam contas de suas ações, possibilitando assim mais transparência ante aos seus atos (PEREIRA, 2008). Um governo será mais accountable, quando sua gestão apresentar maior confiança ante aqueles que lhe deram e/ou delegaram o direito de gerir seus recursos, logo uma gestão responsável e digna de confiança, é uma gestão com um grau maior de accountable (PEREIRA, 2008).

As entidades públicas nacionais são obrigadas por imposição da Constituição Federal, principalmente atendendo ao princípio da publicidade, a tonar público as informações referentes à aplicação dos recursos públicos (PLATT NETO et al., 2005; AVELINO et al. 2010). Nesse contexto, a accountability representa, assim, a obrigação que as organizações e pessoas têm de prestar contas dos resultados obtidos, em função das responsabilidades que decorrem de uma delegação de poder (BISCARO, 2005).

Ribeiro (2009, p. 43-44) por sua vez associa a delegação de poder à accountability, reforçando que ambas podem "ser tratadas como uma relação do tipo principal (sociedade) e agente (governantes) em que o desenho institucional, adotado nessa relação, poderá determinar sua maior ou menor eficiência". Nesta perspectiva, a lei complementar $n^{\circ} 131$, promulgada em 27 de maio de 2009, acrescentou dispositivos à Lei de Responsabilidade Fiscal (LRF) e determinou que a União (Poderes Executivo, Legislativo e Judiciário), Estados, Distrito Federal e Municípios disponibilizem na internet, em tempo real, informações pormenorizadas sobre a execução orçamentária e financeira. Com base nas exigências desta lei, foi formulado o Índice de Transparência dos Estados, cujo objetivo é o de informar o grau de transparência das contas públicas.

As demonstrações contábeis e informações complementares como, por exemplo, àquelas divulgadas por meio de notas explicativas, é parte integrante da prestação de contas dos governos. Nos últimos anos, as normas contábeis aplicadas ao setor público têm sofrido diversas alterações promovidas pela STN, enquanto órgão responsável pela padronização mínima de conceitos e práticas contábeis no âmbito de todas as esferas de governo com vistas à consolidação das contas públicas. A ação da STN, por sua vez, está em consonância com o trabalho desenvolvido no âmbito do Conselho Federal de Contabilidade (CFC) com vistas a promover o desenvolvimento conceitual da Contabilidade aplicada ao setor público, bem como a convergência às normas internacionais (IPSAS). Sendo assim, diversas portarias foram emitidas pela STN que provocarão mudanças substanciais na forma de se fazer a Contabilidade Pública e, consequentemente, nas informações por ela divulgadas. Também, 
houve a emissão de normas pelo CFC, entre elas a NBCT 16.3 que assim define o escopo da evidenciação:

\footnotetext{
A evidenciação deve contribuir para a tomada de decisão e facilitar a instrumentalização do controle social, de modo a permitir que se conheçam o conteúdo, a execução e a avaliação do planejamento das entidades do setor público a partir de dois níveis de análise:

(a) coerência entre os planos hierarquicamente interligados nos seus aspectos quantitativos e qualitativos;

(b) a aderência entre os planos hierarquicamente interligados e a sua implementação.
}

Dantas (2005) afirma que a evidenciação ou disclosure possui um papel fundamental na qualidade da informação, isto é, quanto maior o grau de disclosure possivelmente maior tende a ser a qualidade da informação aos usuários. Nesse contexto, a CVM (1986) afirma que as entidades precisam dar ênfase à evidenciação de todas as informações que permitem a avaliação da sua situação patrimonial e das mutações de seu patrimônio e, além disso, que possibilitem a realização de inferências ante o futuro.

O detalhamento das informações contábeis pode ser um diferencial para entidade. De acordo com Costa e Marion (2007) informações pormenorizadas dos dados financeiros pode melhorar a qualidade das informações contábeis. Neste contexto, informações relacionadas às políticas contábeis adotadas para mensuração dos estoques; o montante total de estoques; o montante de estoques reconhecidos como despesa durante o período; o montante de estoques baixados como perda do período; e etc., por exemplo, são mecanismos de evidenciação que podem auxiliar na gestão dos estoques públicos.

Conjuntamente, órgãos iguais à Controladoria podem auxiliar na preparação e evidenciação das informações contábeis (ARAÚJO; LUCA, 2006). Segundo Suzart et al. (2012), a criação de um órgão de Controladoria auxilia no fornecimento de informações úteis para os gestores públicos. A Controladoria tem um papel importante, pois não auxiliar somente a tomada de decisão, contudo, permite que os gestores públicos desenvolvam mecanismos para monitorar as suas atividades (SUZART et al., 2012). Além disso, a controladoria também torna mais intensa os controles operacionais e administrativos da entidade, especialmente, quanto aos estoques (BIANCHI et al., 2006).

A Controladoria pode possuir diversas funções, dependendo da estrutura e do tipo da organização (SUZART et al., 2012). Neste caso infere-se que o órgão de Controladoria é um órgão público capaz de melhorar os mecanismos de evidenciação das entidades públicas, bem como ensejar um melhor desempenho na gestão de estoques. 


\subsection{DESENVOLVIMENTO DAS HIPÓTESES}

Estudos dirigidos ao setor privado têm buscado relacionar o desempenho, sobretudo, o de caráter econômico-financeiro, com a evidenciação de informações (ver: CLARKSON et al., 2008; SILVA; CARVALHO, 2009; FARIAS; RIBEIRO, 2009; SURROCA; WADDOCK, 2011; PEREIRA et al., 2011; SILVA; ENSSLIN, 2012). Em entidades sem fins lucrativos, principalmente em hospitais, trabalhos dessa natureza também podem ser encontrados (ver: DAVIES; MARSHALL, 1999; MARSHALL et al. 2000; LANSKY, 2002).

Analogamente, esta pesquisa direciona-se a verificar se mecanismos eletrônicos de compras e mecanismos de evidenciação contribuem ou não para o desempenho do setor público, no que concerne à eficiência na gestão de estoques.

Referente aos mecanismos eletrônicos de compras é trabalhado com as subvariáveis portal de compras e sistemas de registro de preços. À CGU (2011) salienta que diante das tantas dificuldades encontradas pelos gestores públicos em relação à aquisição de bens e serviços; ela garante que o sistema de registro de preços é um mecanismo que pode contribuir para a minimização dos custos relacionados aos estoques, em que viabiliza uma espécie de almoxarifado virtual, onde idealmente são efetuados estoques de bens e serviços, sem que haja a necessidade de armazenagem, à qual segundo a literatura da gestão de estoque, é um dos principais custos. De acordo com Fernandes (2007) o sistema de registro de preços frente ao processo burocrático de compras públicas, pode reduzir os custos operacionais de uma ação seletiva, ou seja, um órgão público pode utilizar numa espécie de "carona", o fornecedor de outro órgão da mesma esfera, quando aquele desejar o mesmo produto que este. Cabe salientar que o portal de compras é um pré-requisito para que a entidade possa operar com sistema de registro de preços.

No que tange aos mecanismos de evidenciação ou possíveis elementos de divulgação, trabalha-se com as subvariáveis - evidenciação e detalhamento da conta contábil estoques, órgão de Controladoria e nível de transparência estadual. Este e, os dois primeiros possuem uma relação direta, uma vez que a evidenciação deve ser realizada com o melhor grau de transparência possível. Divulgar especificamente as contas contábeis, segundo a teoria da evidenciação é algo obrigatório a ser realizado pela entidade, pois atende somente o que preconiza as leis e os regulamentos; todavia, informações por menor, da conta contábil podem ser consideradas, uma divulgação de caráter não compulsório. Neste contexto, debates sobre os objetivos da contabilidade têm uma preocupação em estabelecer que a finalidade fundamental da contabilidade seja a de fornecer informações financeiras que possam auxiliar o usuário na sua tomada decisão (SILVA et al., 2009). Portanto, o detalhamento dos 
elementos contábeis, por sua vez, pode dar maior credibilidade à informação (COSTA; MARION, 2007).

A transparência também entendida como um artefato de evidenciação; sinaliza que o governo deve garantir que sejam prestadas aos cidadãos as informações de seu interesse, além das que são obrigatórias por lei ou norma, tão logo estejam disponíveis. Ele deve assegurar que essa comunicação seja feita com clareza e prevalecendo a substância sobre a forma. $\mathrm{O}$ gestor deve buscar uma linguagem acessível ao público-alvo em questão (Transcrição análoga da definição de transparência dada pelo Instituto Brasileiro de Governança Corporativa (2009) para o setor público). O IBGC (2009, p.54-55) reforça que "[...] as informações devem ser equilibradas e de qualidade. A comunicação deve abordar tanto os aspectos positivos quanto os negativos, de modo a oferecer aos interessados uma correta compreensão da organização”.

Crozatti et al. (2006) ao analisarem o ciclo operacional de duas grandes companhias de capital aberto do ramo comercial e industrial, classificaram como sendo satisfatório a relação entre o nível de evidenciação de informações operacionais e o desempenho do ciclo operacional e financeiro de ambas empresas. Portanto, entende-se que a evidenciação e o detalhamento da conta contábil estoques, bem como o nível de transparência possam contribuir para um melhor desempenho na gestão dos estoques públicos. A divulgação de informações, além de garantir a prestação de contas, também pode auxiliar em decisões eficazes relativas às compras, em que pode facilitar a identificação dos consumidores e dos fornecedores de materiais (MARSHALL et al. 2000). Para Marshall et al., (2000), a evidenciação deve ser vista como uma ferramenta de cunho estratégico para melhorar e medir a performance da organização e, deve ser interligada com outras ferramentas, como: treinamento de pessoal, auditoria, controles internos e etc.

No que se refere à Controladoria, ela é um órgão das empresas responsável por preparar e divulgar as informações financeiras da entidade (ARAÚJO; LUCA, 2006). Além disto, a Controladoria tem como uma de suas atribuições, acompanhar de perto os controles internos da empresa e, neste contexto, o controle interno possui uma relação direta com a gestão de estoques. Conforme Oliveira et al. (2002) é pertinente a Controladoria, por exemplo, fornecer métodos adequados de proteção para os ativos da entidade; administrar os custos da organização, inclusive sugerindo mecanismos para redução dos mesmos; analisar e sinalizar as causas que possam prejudicar os sistemas de controle interno da organização, avaliando soluções para os mesmos; analisar de modo adequado a utilização de recursos pela entidade, quer seja materiais, quer seja humanos, buscando a economicidade se possível e etc. De acordo com Biachi (2005) a Controladoria é um órgão capaz de maximizar o nível de 
transparência das informações sobre a organização. A Controladoria pode ser tratada como um mecanismo interno de governança, volvida ao fornecimento de transparência na divulgação de atos e fatos administrativos, capaz de minimizar a assimetria informacional (BIACHI, 2005). Portanto, coligir-se que uma entidade pública, quando possui um órgão de Controladoria, além de melhorar a qualidade de divulgação das suas informações, também pode melhor a qualidade dos seus controles internos, proporcionando um melhor desempenho (BIACHI et al., 2006; SUZART et al., 2012).

Deste modo, essas ideias são resumidas nas seguintes hipóteses a serem testadas por meio da estatística não paramétrica, teste de médias para duas amostras independentes a um intervalo de confiança de $95 \%$, e a um nível de significância de 5\%:

$H_{\text {oa: }}$ mecanismos eletrônicos de compras não contribuem para melhorar o desempenho na gestão de estoques públicos, assim, existe diferença entre o grupo de estados que fazem o uso destes mecanismos, do que não faz.

$H_{o b:}$ mecanismos de evidenciação não contribuem para melhorar o desempenho na gestão de estoques públicos, assim, existe diferença entre o grupo de estados que fazem o uso destes mecanismos, do que não faz.

\section{METODOLOGIA}

\subsection{POPULAÇÃO E COLETA DOS DADOS}

Trata-se de uma pesquisa de abordagem quantitativa, do tipo documental e descritiva, cuja população é composta por todos os 26 estados brasileiros e, mais o Distrito Federal.

Para mensurar a variável - desempenho na gestão de estoques (DEGE) - utilizou-se como proxy, o prazo médio de rotação dos estoques (PMRE), em que foram apurados os valores referentes a: estoque inicial, compras e estoque final, das contas: material de consumo e material de distribuição gratuita. Estes números contábeis foram obtidos nos balanços orçamentários e patrimoniais dos estados, disponíveis no banco de dados: FINBRA, divulgado na website da Secretaria do Tesouro Nacional (STN), todos referentes aos anos de 2007 a 2010 (4 anos). O PMRE é considerado um dos importantíssimos quocientes para a análise da rotatividade ou de giro de ativos, sobretudo os estoques, em que "seus resultados normalmente são apresentados em dias, meses ou períodos maiores, fracionários de um ano”. (IUDÍCIBUS, 2009, p. 100). A literatura sobre análise de balanços ratifica que quanto menor forem os dias de renovação dos estoques, melhor a gestão deste item do ativo e, mais eficiente é o controle interno da organização. Neste contexto, os estados foram divididos em dois grupos basicamente. Esta divisão foi realizada tomando como ponto de "corte" o valor da 
mediana (103 dias), portanto, abaixo da mediana, foram considerados os estados, de "melhor desempenho" (G $\left.\mathrm{G}_{\mathrm{DEGE} 1}\right)$ e, acima da mediana, os estados, de "pior desempenho" (GEGE2).

Para construção da variável - mecanismos eletrônicos de compra (MEC) - são utilizadas as subvariáveis: portal de compras (POCO); e sistema de registro de preços (SIRP). A variável - mecanismos de evidenciação (MEV) - foi definida pelas subvariáveis: evidenciação da conta contábil de estoques (ECCE); detalhamento da conta contábil de estoques (DCCE); órgão de controladoria (OCON); e nível de transparência estadual (NITE).

Para a aferição das subvariáveis: POCO, SIRP, ECCE, DCCE e OCON, uma análise de conteúdo foi realizada nas websites dos estados, bem como nos relatórios financeiros anuais dos governos estaduais respectivamente. A subvariável índice de transparência dos estados (NITE) foi coletada por meio do portal: Índice de Transparência. Ressalta-se, que do mesmo modo em que foi realizado com a variável, desempenho na gestão de estoques; realizou-se com a subvariável, NITE, ou seja, utilizou-se a mediana (5 pontos) para dividir os estados em dois grupos: acima da mediana, estados com "maior grau" de transparência (GITE1) e, abaixo da mediana, estados com “menor grau” de transparência (G G $_{\text {NTE2 }}$ ).

De modo mais detalhado, apresenta-se no Quadro 1 às variáveis e suas subdivisões:

\section{Quadro 1 - Descrição das Variáveis do Estudo}

\begin{tabular}{|c|c|c|}
\hline Variáveis & Subvariáveis & Descrição \\
\hline 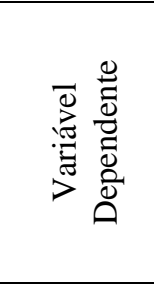 & $\begin{array}{l}\text { Desempenho na } \\
\text { Gestão de Estoques } \\
(D E G E)\end{array}$ & $\begin{array}{l}\text { Variável mensurada a partir do cálculo do PMRE = Estoque Final/ } \\
\text { Consumo Anual } x 360 \text {, calculado com base em informações extraídas dos } \\
\text { Balanços Orçamentários e Patrimoniais. Esta variável com base na } \\
\text { mediana do PMRE divide a população em dois grupos. Grupo } 1 \text { - estados } \\
\text { com melhor desempenho ("1") na gestão de estoques, e Grupo }{ }_{2}-\text { estados } \\
\text { com pior desempenho ("0"). Portanto, trata-se de uma variável binária ou } \\
\text { dicotômica. }\end{array}$ \\
\hline \multirow{2}{*}{ 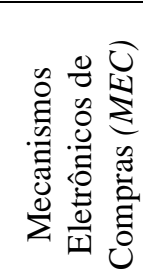 } & $\begin{array}{l}\text { Portal de Compras } \\
\qquad(P O C O)\end{array}$ & $\begin{array}{l}\text { Esta variável determina se o Estado possui ou não portal de compras. } \\
\text { Pergunta binária (" } 1 \text { " caso positivo e "0" caso contrário). }\end{array}$ \\
\hline & $\begin{array}{l}\text { Sistema de Registro } \\
\text { de preços }(S I R P)\end{array}$ & $\begin{array}{l}\text { Esta variável determina se o Estado possui ou não sistema de registro de } \\
\text { preços. Pergunta binária ("1" caso positivo e " } 0 \text { " caso contrário). }\end{array}$ \\
\hline \multirow{4}{*}{ 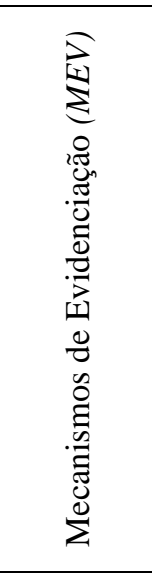 } & $\begin{array}{l}\text { Evidenciação da } \\
\text { Conta de Estoques } \\
(E C C E)\end{array}$ & $\begin{array}{l}\text { Esta variável determina se o Estado faz a evidenciação da conta contábil } \\
\text { de estoques/almoxarifados em seus relatórios anuais financeiros. Pergunta } \\
\text { binária (" } 1 \text { " caso positivo e " } 0 \text { " caso contrário). }\end{array}$ \\
\hline & $\begin{array}{l}\text { Detalhamento da } \\
\text { Conta de Estoques } \\
(D C C E)\end{array}$ & $\begin{array}{l}\text { Esta variável determina se o Estado faz o detalhamento da conta contábil } \\
\text { de estoques/almoxarifados em seus relatórios anuais financeiros. Pergunta } \\
\text { binária (" } 1 \text { " caso positivo e " } 0 \text { " caso contrário). }\end{array}$ \\
\hline & $\begin{array}{l}\text { Órgão de } \\
\text { Controladoria } \\
(\text { OCON })\end{array}$ & $\begin{array}{l}\text { Esta variável verifica se o Estado possui ou não um órgão de } \\
\text { controladoria. Pergunta binária (" } 1 \text { " caso positivo e "0" caso contrário). }\end{array}$ \\
\hline & $\begin{array}{l}\text { Nível de } \\
\text { Transparência dos } \\
\text { Estados }(I T E)\end{array}$ & $\begin{array}{l}\text { Esta variável verifica o nível de transparência do estado com base na } \\
\text { mediana do Índice de Transparência Estadual divulgado pela FGV. } \\
\text { Pergunta binária: estados acima da mediana "1" (maior nível de } \\
\text { transparência estadual); estados abaixo da mediana "0" (menor nível de } \\
\text { transparência estadual). }\end{array}$ \\
\hline
\end{tabular}




\subsection{TÉCNICAS DE ANÁLISES DOS DADOS}

As técnicas de análise dos dados são conduzidas por meio das estatísticas descritivas, matriz de correlação, e por meio do teste não paramétrico, teste de médias para duas amostras independes.

Estatísticas descritivas. É realizada com o objetivo de identificar qual é o número de estados que possuem ou não portal de compras e sistemas de registro de preço; quais realizam ou não a evidenciação e o detalhamento da conta de estoques, bem como demonstrar o comportamento do desempenho na gestão de estoques dos estados e, os seus respectivos índices de transparência.

Matriz de correlação. Tem como objetivo verificar se existe correlação entre as variáveis e subvariáveis de modo estatisticamente significativo.

Teste de médias para duas amostras independentes. Utilizado para comparar os dois grupos independentes de estados quanto ao desempenho na gestão de estoques, em que o Grupo $_{1}$ - contém os estados com "melhor desempenho" e o Grupo 2 - contém os estados com "pior desempenho", conforme já detalhado anteriormente. Este teste é utilizado para testar as duas hipóteses gerais do estudo, a partir do valor estatístico do Mann-Whitney $U$.

\section{RESULTADOS}

$\mathrm{Na}$ Tabela 1 é ilustrado de modo regional o desempenho (PMRE) dos estoques públicos estaduais ao longo do período de investigação do estudo.

\section{Tabela 1 - Desempenho dos estoques públicos por meio do PMRE}

\begin{tabular}{cccccccc}
\hline Regiões & 2007 & 2008 & $\mathrm{AH} \%$ & 2009 & $\mathrm{AH} \%$ & 2010 & $\mathrm{AH} \%$ \\
\hline Norte & 140 & 188 & 34,30 & 234 & 24,82 & 237 & 1,36 \\
Nordeste & 66 & 43 & $-35,70$ & 78 & 83,29 & 78 & $-0,02$ \\
Sudeste & 245 & 222 & $-9,41$ & 306 & 38,22 & 330 & 7,61 \\
Centro Oeste & 86 & 64 & $-25,14$ & 161 & 151,74 & 226 & 40,11 \\
Sul & 100 & 78 & $-22,55$ & 86 & 10,79 & 91 & 5,16 \\
\hline
\end{tabular}

Por meio da análise horizontal (AH) verifica-se que o PMRE da Região Norte apresentou um crescimento de 34,30\% de 2007 para 2008 e, de 24,82\% de 2008 para 2009 e, de 1,36\% de 2009 para 2010. Na Região Nordeste, o PMRE teve uma redução substancial em 2008, mas em 2009, o PRME ultrapassou os patamares observados em 2007 e, em 2010 houve um tímido arrefecimento. A redução nos prazos de renovação de estoques, em 2008 , também é observada nas regiões Sudeste, Centro-Oeste e Sul, de maneira mais fraca no 
Sudeste. Em 2009 e 2010, o desempenho na gestão de estoques piora com índices mais expressivos na região Centro-Oeste. De 2008 para 2009, os prazos mais do que dobram nesta região. De maneira geral, a região com melhor desempenho quanto à gestão de estoques é a Sul e as piores, regiões Norte e Sudeste, nesta ordem.

Na Tabela 2 são demonstradas as estatísticas descritivas dos indicadores de PMRE e NITE. Os estados renovaram os seus estoques numa média de 180 dias. A menor quantidade de dias, em que os estados conseguiram renovar os seus estoques ficou no patamar de 33 dias, número apresentado pelo Estado do Amazonas. Ao passo que a maior quantidade de giro, foi de 660 dias, registrado no Estado de Rondônia.

Tabela 2 - Estatística descritiva do prazo médio de rotação de estoques e do índice de transparência dos estados

\begin{tabular}{ccccc|ccc}
\hline \multirow{2}{*}{ Variáveis } & \multirow{2}{*}{ Média } & \multirow{2}{*}{ Desvio Padrão } & \multirow{2}{*}{ Mínimo } & \multirow{2}{*}{ Máximo } & \multicolumn{3}{|c}{ Quartis } \\
\cline { 5 - 6 } & & & & $25 \%$ & $50 \%$ & $75 \%$ \\
PMRE & 180 & 178 & 33 & 660 & 47 & 104 & 326 \\
ITE & 4,87 & 1,0 & 3,04 & 6,96 & 3,93 & 5,07 & 5,38 \\
\hline
\end{tabular}

Legenda: PMRE = Prazo Médio de Rotação de Estoques; ITE = Índice de Transparência Estadual.

A média do índice de transparência entre os estados é de, aproximadamente, 4,87 pontos. O mínimo de pontos atingidos foi de 3,04, este pelo Estado de Piauí e, o máximo foi de 6,96 pontos, alcançado pelo Estado de São Paulo.

Utilizando-se dos resultados apresentados por meio dos quartis, percebe-se que dentre os 27 estados, $25 \%$ deles obtiveram um giro de estoques de até 47 dias; a metade deles até 104 dias; 75\% dos estados renovaram os seus estoques, em mais 326 dias. Quanto ao índice de transparência, verifica-se que $25 \%$ dos estados estão numa escala próximo a quatro pontos, $75 \%$ exatamente com cinco pontos e, $25 \%$ acima da escala de cinco pontos.

Na Tabela 3 são apresentadas as estatísticas descritivas referentes à análise dicotômica ou binária das variáveis e subvariáveis levantadas na pesquisa.

Observa-se na Tabela 3, que mais de 50\% dos estados apresentaram um desempenho na gestão de estoques considerado “melhor", 48,15\% consequentemente “pior”. Dos 27 estados, 40,7\% não possuem portal de compras. O mesmo ocorrendo com o sistema de registro de preço. Consequentemente, todos os estados com sistema de registro de preços possuem portal de compras, já que este é um pré-requisito para o funcionamento daquele. Nos aspectos relativos à evidenciação e detalhamento dos estoques, a Tabela 3 indica que, em $70,4 \%$ dos estados, a conta estoque é divulgada nos seus relatórios contábeis e, em 29,6\%, apesar de ser demonstrado o valor da conta estoques, ele aparece em conjunto com outros elementos patrimoniais. Quanto ao detalhamento da conta estoques, percebe-se que $85,20 \%$ 
dos estados brasileiros não detalharam a conta de estoques/almoxarifados, portanto, apenas 14,80\% fazem este detalhamento, inclusive fazendo a divulgação em separado dos estoques, bem como mencionando o critério de avaliação de seus estoques. Contudo, isto talvez ocorra, porque, no setor público brasileiro, as contas normalmente são divulgadas a partir do quarto nível, devido ainda não haver uma padronização nacional; a conta estoque pode não aparecer simplesmente por conta do nível obrigatório no ente e, não por uma decisão gerencial. Porém, espera-se que isto mude em decorrência da adoção das normas internacionais de contabilidade aplicada ao setor público. Mais de 55\% dos estados brasileiros possuem um órgão interno de controladoria, ao menos é o que indica o portal de cada governo pesquisado; onze dos 27 estados ao que tudo indica, não possuem um órgão de controladoria. Basicamente $50 \%$ dos estados brasileiros apresentaram um nível de transparência alto e a mesma quantidade apresentou um nível de transparência considerado baixo.

Tabela 3 - Estatísticas descritivas da análise binária das variáveis e subvariáveis levantadas na pesquisa

\begin{tabular}{|c|c|c|c|c|}
\hline Variáveis & Subvariáveis & "1" Sim “0” Não & Frequência & $\%$ \\
\hline \multirow{2}{*}{\multicolumn{2}{|c|}{ DEGE* }} & "1" & 14 & 51,85 \\
\hline & & “0” & 13 & 48,15 \\
\hline \multirow{4}{*}{ MEC } & \multirow{2}{*}{ POCO } & "1" & 16 & 59,30 \\
\hline & & "0" & 11 & 40,70 \\
\hline & \multirow{2}{*}{ SIRP } & "1" & 16 & 59,03 \\
\hline & & "0" & 11 & 40,07 \\
\hline \multirow{8}{*}{ AEV } & \multirow{2}{*}{ ECCE } & "1" & 19 & 70,38 \\
\hline & & "0" & 8 & 29,62 \\
\hline & \multirow{2}{*}{ DCCE } & "1" & 4 & 14,81 \\
\hline & & "0" & 23 & 85,19 \\
\hline & \multirow{2}{*}{ OCON } & "1" & 16 & 59,30 \\
\hline & & “0” & 11 & 40,70 \\
\hline & \multirow{2}{*}{ NITE** $^{* *}$} & "1" & 14 & 51,85 \\
\hline & & "0" & 13 & 48,15 \\
\hline
\end{tabular}

*melhor desempenho $=1$; pior desempenho $=0$. **maior nível de transparência $=1$; menor nível de transparência $=0$.

Na Tabela 4 é ilustrada a relação do GEDE com o POCO e SIRP, tomando como base a frequência. De 11 estados que não portal de compras e sistema de registro de preços, oito deles apresentaram "pior desempenho", ao passo que apenas três deles apresentaram "melhor desempenho". Quanto aos 16 estados que possui portal de compras e sistema de registro de preços, 11 deles apresentaram "melhor desempenho", enquanto que cinco deles "pior desempenho".

Tabela 4 - Estatísticas descritivas: GEDE $x$ POCO e SIRP 


\begin{tabular}{ccc}
\hline Portal de Compras/Sistema de Registro de Preços & Não Possuí & Possuí \\
\hline Melhor Desempenho & 3 & 11 \\
Pior Desempenho & 8 & 5 \\
Total & 11 & 16 \\
\hline
\end{tabular}

Na Tabela 5 é ilustrada a relação do GEDE com o ECCE, tomando como base a frequência. De oito estados que não fizeram a evidenciação da conta de estoques, cinco deles apresentaram "pior desempenho" e, três deles "melhor desempenho". Quanto aos 19 que fizeram a evidenciação, 11 deles apresentaram "melhor desempenho", enquanto que oito deles "pior desempenho".

Tabela 5 - Estatísticas descritivas: DEGE $x$ ECCE

\begin{tabular}{ccc}
\hline Evidenciação da Conta Contábil de Estoques & Não Faz & Faz \\
\hline Melhor Desempenho & 3 & 11 \\
Pior Desempenho & 5 & 8 \\
Total & 8 & 19 \\
\hline
\end{tabular}

Na Tabela 6 é ilustrada a relação do GEDE com o DCCE, tomando como base a frequência. De 23 estados que não fizeram o detalhamento da conta de estoques, 12 deles apresentaram "pior desempenho", enquanto que 11 deles "melhor desempenho". Quanto aos estados que fizeram o detalhamento da conta de estoques, três deles apresentaram "melhor desempenho", enquanto que um apenas "pior desempenho".

Tabela 6 - Estatísticas descritivas: DEGE $x$ DCCE

\begin{tabular}{ccc}
\hline Detalhamento da Conta de Estoques & Não Faz & Faz \\
\hline Melhor Desempenho & 11 & 3 \\
Pior Desempenho & 12 & 1 \\
Total & 23 & 4 \\
\hline
\end{tabular}

Na Tabela 7 é ilustrada a relação do DEGE com o DCON, tomando como base a frequência. Observa-se que dentre os 14 estados que apresentou "melhor desempenho", nove deles possuem órgão de controladoria, sete deles não possuem. Dos 13 que apresentaram "pior desempenho", cinco deles possuem órgão de Controladoria, seis deles não possuem este órgão.

Tabela 7 - Estatísticas descritivas: GEDE $x$ DCON

\begin{tabular}{ccc}
\hline Órgão de Controladoria & Possuí & Não Possuí \\
\hline Melhor Desempenho & 9 & 7 \\
Pior Desempenho & 5 & 6 \\
Total & 14 & 13 \\
\hline
\end{tabular}


Na Tabela 8 é ilustrada a relação do DEGE com o NITE, tomando como base a frequência. Observa-se que dentre os estados que apresentou "pior desempenho", nove deles apresentam "menor grau" de transparência e, cinco deles "maior grau" de transparência. Dentre os estados que apresentou "melhor desempenho", cinco deles apresentam "menor grau" de transparência e, oito deles "maior grau" de transparência.

Tabela 8 - Estatísticas descritivas: DEGE $x$ NITE

\begin{tabular}{ccc}
\hline Índice de Transparência Estadual & Menor Grau & Maior Grau \\
\hline Pior Desempenho & 9 & 5 \\
Melhor Desempenho & 5 & 8 \\
Total & 14 & 13 \\
\hline
\end{tabular}

Na Tabela 8 é ilustrada a matriz de correlação das variáveis/subvariáveis levantadas na pesquisa. Os resultados demonstrados indicam que a variável - gestão no desempenho de estoques - não possui correlação com nenhuma subvariável, das variáveis, mecanismos eletrônicos de compras e, mecanismos de evidenciação. Portanto, a priori, isto sinaliza que o desempenho na gestão de estoques não possui correlação direta com nenhumas das subvariáveis levantadas.

Tabela 8 - Matriz de correlação das variáveis: Spearman's rho $(\mathrm{n}=27)$

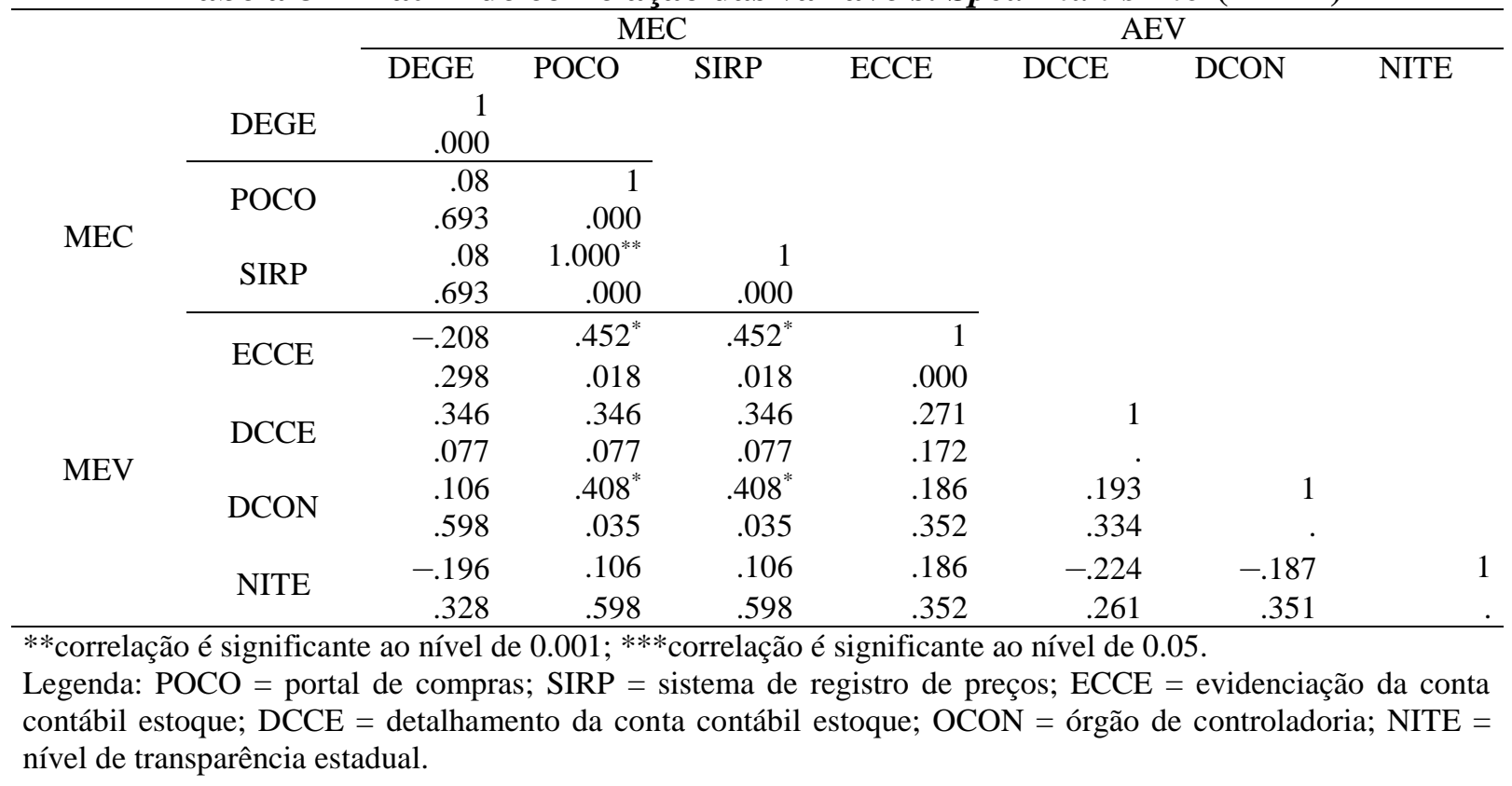

$\mathrm{Na}$ Tabela 9 são apresentados os resultados do teste de médias para duas amostras independentes. Verifica-se que nenhuma das variáveis se mostrou estatisticamente significativa. A partir do teste de Mann-Whitney, todas elas apresentaram p-value acima de 
$5 \%$ ( $p$-value > .005). Com base nesse achado, as hipóteses nulas: $\mathrm{H}_{0 \mathrm{a}} \mathrm{e} H_{0 b}$ não podem ser rejeitadas a um nível de significância de $5 \%$.

Tabela 9 - Teste de médias para duas amostras independentes: Mann-Whitney $U(\mathrm{n}=$ 27)

\begin{tabular}{cccc}
\hline Variáveis & Subvariáveis & Valor da Estatistica & $P$-value \\
\hline Mecanismos Eletrônicos & POCO & 81,000 & .685 \\
de Compras & SIRP & 81,00 & .685 \\
\hline & $E C C E$ & 71,00 & .289 \\
Mecanismos de & DCCE & 66,00 & .078 \\
Evidenciação & OCON & 78,500 & .588 \\
& NITE & 70,500 & .319 \\
\hline
\end{tabular}

Legenda: POCO = portal de compras; SIRP = sistema de registro de preços; ECCE = evidenciação da conta contábil estoque; DCCE = detalhamento da conta contábil estoque; OCON = órgão de controladoria; NITE = nível de transparência estadual.

Deste modo, o que se pode inferir a partir destes resultados é que mecanismos eletrônicos de compras (portal de compras e sistema de registro preços) e mecanismos de evidenciação (evidenciação da conta contábil estoque, detalhamento da conta contábil estoque, órgão de Controladoria e nível de transparência) não contribuem para diferenciar estados brasileiros que "possuem melhor" ou "pior desempenho" na gestão de estoques. O achado é mais bem discutido na seção 5 .

\section{DISCUSSÃO E CONCLUSÃO}

A gestão dos estoques públicos ainda é algo preocupante na nova administração pública. Apesar de diversos estudos já terem recomendados alguns métodos para ressuprimento e distribuição dos estoques. Nas entidades públicas ainda é possível observar o desgoverno dos estoques, quer seja pelo seu superdimensionamento, quer seja pelo seu subdimensionamento. Mecanismos eletrônicos de compras criados para minimizar os problemas relacionados à gestão dos estoques públicos (portal de compras e sistema de registro de preços), ainda não foi implantado por todas as entidades públicas brasileiras, sobretudo, pelos estados, indicando que muitos governos ainda não se preocupam com a gestão dos seus suprimentos de materiais. Conjugado a isto, ainda existe a omissão de informações contábeis relativas à conta contábil de estoques, o que impede o acompanhamento do controle operacional deste ativo. Mecanismos de evidenciação para melhorar as informações relativas a esta conta podem ser utilizadas, inclusive o seu detalhamento. Órgãos internos, caso da Controladoria pode auxiliar os gestores a melhorarem a qualidade de suas informações, além de auxiliar no controle interno efetivo dos estoques, o 
que poderia gerar mais economicidade dos recursos públicos, além de aumentar o seu nível de transparência.

A partir desta perspectiva, realizou-se primeiramente uma avaliação do desempenho da gestão dos estoques dos estados brasileiros por meio do prazo médio de rotação (PMRE). Percebeu-se deste modo, que a mediana de giro em dias, dos estoques públicos estaduais é igual a 103 dias (3,4 meses). Tomando-se como base este valor, dividiram-se os estados em dois grupos basicamente: grupo de "melhor desempenho" na gestão dos estoques e (acima da mediana), grupo de "pior desempenho" na gestão dos estoques (abaixo da mediana). Esta metodologia permitiu a consecução do objetivo da pesquisa, que consistiu em verificar se mecanismos eletrônicos de compras e mecanismos de evidenciação contribuem para melhorar o desempenho na gestão dos estoques públicos. Os resultados empíricos encontrados não suportam esta ideia. Primeiramente verificou-se que o grupo de estados que possuem portal de compras e utilizam sistema de registro de preços não conseguem ser diferentes estatisticamente do grupo de estados que não possuem o portal e, nem utilizam o SRP no que tange o desempenho da gestão de estoques. Seguidamente, do mesmo modo, o grupo de estados que fazem a evidenciação e o detalhamento da conta contábil estoques, que possuem um órgão de controladoria e, que conseguiram apresentar um nível maior de transparência, não conseguiu se diferenciar de modo estatístico, do grupo de estados que não fazem a evidenciação e o detalhamento da conta contábil estoques, que não possuem órgão de controladoria e, apresentam um nível menor de transparência estadual.

Neste contexto, os resultados indicados faz com que as hipóteses norteadoras do artigo não sejam rejeitadas; além de ser contrário com o que afirma a literatura sobre mecanismos eletrônicos de compras, à qual ratifica - que o portal de compras e o sistema de registro de preços contribuem para o melhoramento do desempenho na gestão dos estoques públicos (ver: MORESI, 2000; SALDANDHA, 2006; FERNANDES, 2007; CARVALHO, 2008; FREITAS, 2008; CGU, 2011). Bem como a literatura sobre evidenciação e, que também trata da controladoria, quando afirma que - a qualidade da divulgação pode impactar positivamente o desempenho da entidade (ver: DAVIES; MARSHALL, 1999; MARSHALL et al. 2000; LANSKY, 2002; CROZATTI et al., 2006) e, quanto a Controladoria que - pode auxiliar na produção de melhores informações contábeis e, de modo igual no controle operacional dos estoques (ver: OLIVEIRA et al., 2002; ARAÚJO; LUCA, 2006; BIACHI, 2005; BIANCHI et al., 2006; SUZART et al., 2012).

Não obstante, salienta-se que talvez a quantidade média de giro de estoques encontrada no trabalho (180 dias - 6 meses), não seja de fato a melhor indicação de um 
desempenho na gestão de estoques no caso do setor público, uma vez que a teoria sobre análise de balanço menciona - quanto menor for à quantidade de dias, mais eficiente é a gestão dos estoques. Portanto, isto pode impactar diretamente os resultados encontrados, quanto à gestão dos estoques públicos dos estados brasileiros; pois realmente este número pode indicar que nenhuns dos estados apresentam gestão eficiente, entretanto, passa ser válido quando se avalia o "mais eficiente" e o "menos eficiente" quanto à gestão dos estoques.

Contudo, o estudo contribui para literatura sobre a gestão de estoques públicos e, a respeito da evidenciação no setor público, permitindo concluir-se que independente de alguns dos estados brasileiros possuírem mecanismos de compras eletrônicas ou utilizar-se de mecanismos de evidenciação, eles não conseguem se diferenciar de forma estatisticamente significativa dos demais estados com ausência destes mecanismos.

Oportunamente, pesquisas futuras sobre assunto podem utilizar outros mecanismos para medir o desempenho da gestão dos estoques públicos, bem como realizar um estudo com um período mais estendido, na tentativa de aumentar os números de casos a serem observados, consequentemente métodos estatísticos mais robustos. A evidenciação também pode ser trabalhada de forma diferente, não focando somente a divulgação da conta contábil estoque, o que ainda é bastante limitado, nos demonstrativos financeiros anuais dos governos; métricas de informações financeiras e não financeiras são interessantes (ver: MELLO, 2009; MENESES; PETER, 2012).

\section{REFERÊNCIAS}

ARAÚJO, P. G. L.; LUCA, M. Controladoria e gerenciamento do risco operacional: um estudo nas grandes empresas do Estado do Ceará. In: Congresso USP de Contabilidade, 6, 2006, São Paulo. Anais...VI Congresso USP de Contabilidade: São Paulo, 2006. CD-ROM.

AVELINO, B. C.; COLAUTO, R. D.; ANGOTTI, M. Política de evidenciação de informações do setor público no Estado de Minas Gerais. In: Congresso USP de Contabilidade e Controladoria, 10, 2010, São Paulo. Anais... X Congresso USP de Contabilidade e Controladoria, USP: São Paulo, 2010.

BIANCHI, M. A controladoria como um mecanismo interno de governança corporativa e de redução dos conflitos. Dissertação (Mestrado em Ciências Contábeis). Universidade Vale dos Sinos: São Leopoldo, 2005.

BIANCHI, M.; BACKES, R. G.; GIONGO, J. A participação da controladoria no processo de gestão organizacional. Contexto. Vol. 6, n. 10, 2006. 
BISCARO, E. T. (2005). Accountability em unidade de negócios: um estudo de caso. 2005. Dissertação (Mestrado em Contabilidade) - Universidade Regional de Blumenau: Blumenau, 2005.

BOTTER, R.; FORTUIN, L. Stocking strategy for service parts: a case study. International Journal of Operations \& Production Management, v. 20, n. 6, pp. 656-674, 2000.

BRASIL. LEI COMPLEMENTAR N 101, DE 4 DE MAIO DE 2000. (2000). Estabelece normas de finanças públicas voltadas para a responsabilidade na gestão fiscal e dá outras providências. Disponível em: < http://www.planalto.gov.br/ccivil_03/Leis/LCP/Lcp101.htm>. Acesso em: 15 abr. 2010.

BRASIL. LEI COMPLEMENTAR No 131, DE 27 DE MAIO DE 2009. (2009). Acrescenta dispositivos à Lei Complementar $n^{0} 101$, de 4 de maio de 2000, que estabelece normas de finanças públicas voltadas para a responsabilidade na gestão fiscal e dá outras providências, a fim de determinar a disponibilização, em tempo real, de informações pormenorizadas sobre a execução orçamentária e financeira da União, dos Estados, do Distrito Federal e dos Municípios. Disponível em: < http://www.planalto.gov.br/ccivil_03/Leis/LCP/Lcp131.htm>. Acesso em: 20 Jul. 2011.

BRASIL. LEI No 4.320, de 17 de MARÇO de 1964. (1964). Estatui Normas Gerais de Direito Financeiro para elaboração e controle dos orçamentos e balanços da União, Estados, Municípios e Distrito Federal. Brasília, 1964. Disponível em: <http://www.planalto.gov.br/ccivil_03/Leis/L4320.htm> Acesso em: 15 abr. 2011.

BRASIL. LEI No 8.666, DE 21 DE JUNHO DE 1993. (1993). Regulamenta o art. 37, inciso XXI, da Constituição Federal, institui normas para licitações e contratos da Administração Pública e dá outras providências. Disponível em: <http://www.planalto.gov.br/ccivil_03/Leis/L8666cons.htm>. Acesso em: 15 abr. 2011.

BRASIL. LEI No 10.520, DE 17 DE JULHO DE 2002. (2002). Institui, no âmbito da União, Estados, Distrito Federal e Municípios, nos termos do art. 37, inciso XXI, da Constituição Federal, modalidade de licitação denominada pregão, para aquisição de bens e serviços comuns, e dá outras providências. Disponível em: < http://www.planalto.gov.br/ccivil_03/Leis/2002/L10520.htm>. Acesso em: 15 abr. 2011.

CARVALHO, C. H. S. Os efeitos do sistema de registro de preço nas compras públicas: estudo de caso da secretaria municipal de obras, serviços básicos e habitação da cidade de Manaus. 2008. Dissertação (Mestrado em Administração Pública) - Fundação Getúlio Vargas: Rio de Janeiro, 2008.

CLARKSON, P. M.; LI, Y.; RICHARDSON, G. D.; VASVARI, F. P. Revisiting the relation between environmental performance and environmental disclosure: an empirical analysis. Accounting, Organizations and Society. Vol. 33, pp. 303-327, 2008.

Comissão de Valores Imobiliários. DELIBERAÇÃO CVM N²9, De 05 De Fevereiro de 1986. (1986). Disponível em:

<http://www.cvm.gov.br/asp/cvmwww/atos/exiato.asp?File=/deli/deli029.htm > Acesso em: 20 abr. 2011. 
Conselho Federal de Contabilidade. NBC T 16 - Normas brasileiras de contabilidade aplicadas ao setor público. Brasília, 2008. (2008). Disponível em 〈http://www.cfc.gov.br $>$ Acesso em: 18 abr. 2011.

COSTA, R. S.; MARION, J. C. A uniformidade na evidenciação das informações ambientais. R. Cont. Fin, N. 43, pp. 20 - 33, 2007.

CROZATTI; J.; CORDEIRO, A. A. L.; CAMPOS, P. A. C. Efeitos falta de evidenciação nas demonstrações contábeis publicadas para determinação e análise do ciclo operacional e financeiro pelo usurário externo. In: Congresso USP de Contabilidade, 6, 2006, São Paulo. Anais...VI Congresso USP de Contabilidade: São Paulo, 2006.

DANTAS, J. A.; ZENDERSKY, H. C.; NIYAMA, J. K. A dualidade entre os benefícios do disclosure e a relutância das organizações em aumentar o grau de evidenciação. E \& $\mathbf{G}$ Economia e Gestão. Vol. 5, pp. 56-76, 2005.

DAVIES, H. T. O.; MARSHALL, M. N. Public disclosure of performance data: does the public get what the public wants? The Lancet. Vol. 353, pp. 1.639-1640, 1999.

FERNANDES, C. C. C. (2003). Transformações na gestão de compras da administração pública brasileira. In: Congreso Internacional Del Clad Sobre La Reforma Del Estado Y De La Administración Pública, ago. Panamá, 2003.

FARIAS, K. T. R.; RIBEIRO, S. M. A relação entre divulgação ambiental, desempenho ambiental e Desempenho econômico nas empresas brasileiras de capital aberto: uma pesquisa utilizando equações simultâneas. In: Congresso IAAER-ANPCONT, 3, 2009, São Paulo. Anais... III IAAER-ANPCONT: São Paulo, 2009.

FERNANDES, J. U. J. Carona em sistema de registro de preços: uma opção inteligente para a redução de custos e controle. Fórum de Contratação e Gestão Pública, Belo Horizonte, Vol. 6, 2007.

FREITAS, F. F. T.; MEDEIROS, C. V. S.; MELO, A. C. S. Aplicação de técnicas de gestão de estoques, como auxílio à tomada de decisões em compras públicas estaduais de medicamentos. In: Encontro Nacional de Engenharia de Produção, 18, 2008, Rio de Janeiro. Anais... XXVIII Encontro Nacional de Engenharia de Produção: São Paulo: 2008.

GOULART, A. M. C. (2003). Evidenciação contábil do risco de mercado por instituições financeiras no Brasil. 2003. Dissertação (Mestrado em Contabilidade) - Faculdade de Economia, Administração/Universidade de São Paulo. São Paulo: São Paulo, 2003.

Instituto Brasileiro de Governança Corporativa - IBGC. Código das Melhores Práticas de Governança Corporativa. $4^{a}$ ed. São Paulo, 2009. (2009). Disponível em:

<http://www.ibgc.org.br> Acesso em: 23 abr. 2011.

IUDÍCIBUS, S. (2009). Análise de Balanços. São Paulo: Atlas, 2009.

IUDÍCIBUS, S.; MARION, J. C.(2002). Introdução à Teoria da Contabilidade. $3^{\mathrm{a}}$ ed. São Paulo: Atlas. 
SUZART, J. A. S.; MARCELINO, C. V.; ROCHA, J. S. Brazilian public controllership institutions - theory versus practice. International Business Research; Vol. 5, pp. 184-194, 2012.

LANSKY, D. Improving quality through public disclosure of performance information. Health Affairs. Vol. 21, pp. 52-62, 2002.

LANZANA, A. P.; SILVEIRA, A. D-M.; FAMÁ, R. Existe relação entre disclosure e governança corporativa no Brasil?. In: ENCONTRO DA ANPAD, 30., 2006, Salvador. Anais... Salvador, ANPAD, 2006. CD-ROM.

MARSHALL, M. N.; SHEKELLE, P. G.; LEATHERMAN, S.; BROOK, R. H. Public disclosure of performance data: learning from the US experience. Qual Health Care, Vol. 9, pp. 53-57, 2000.

MELLO, G. R. Estudo das práticas de governança eletrônica: instrumento de controladoria para a tomada de decisões na gestão dos estados brasileiros. 2009. Tese (Doutorado em Contabilidade) - Faculdade de Economia, Administração/Universidade de São Paulo: São Paulo, 2009.

MENESES, A. F.; PETER, M. G. A. Evidenciação das demonstrações contábeis: estudo sob a óptica do processo de convergência das normas de contabilidade aplicadas ao setor público.

Revista Gestão Pública: Práticas e Desafios, Vol. 3, pp. 1-23, 2012.

MORESI, E. A. D. Delineando o valor do sistema de informação de uma organização. Ci. Inf. Brasília, Vol. 29 pp. 14-24, 2000.

MOURA, C. E. Gestão de Estoques. 1 ${ }^{\text {a }}$. Ed. Rio de Janeiro: Editora Ciência Moderna Ltda., 2004.

OLIVEIRA, L. M.; PEREZ JR., J. H.; SILVA, C. A. S. Controladoria Estratégica. São Paulo: Atlas, 2002.

PACE.; E. S. U.; BASSO, L. F. C. B.; SILVA, M. A. Indicadores de desempenho como direcionadores de valor. Rev. adm. contemp. Vol. 7, 2003.

PEREIRA, G.; CARVALHO, F. N.; PARENTE, E.G. V. Desempenho econômico e evidenciação ambiental: análise das empresas que receberam o prêmio rumo à credibilidade 2010. Revista do Conselho Regional de Contabilidade de Santa Catarina, Vol. 10, 2011.

PINHO, J. A. G.; SACRAMENTO, A. R. S. Accountability: já podemos traduzi-la para o português?. Rev. Adm. Pública, Rio de Janeiro, v. 43, 2009.

PLATT NETO, O. A. P.; CRUZ, F.; ENSSLIN, S. R.; ENSSLIN, L. Publicidade e Transparência das Contas Públicas: obrigatoriedade e abrangência desses princípios na administração pública brasileira. Contab. Vista \& Rev., Vol. 18, pp. 75-94, 2007.

RIBEIRO, D. C. Sistema de controle dos gastos públicos do governo federal: uma ênfase no programa bolsa família. 2009. Tese (Doutorado em Contabilidade) - Faculdade de Economia, Administração/Universidade de São Paulo. São Paulo, 2009. 
SANTOS, C. S. Introdução à gestão pública. São Paulo: Saraiva, 2006.

SECRETÁRIA DO TESOURO NACIONAL. Manual técnico de contabilidade aplicada ao setor público: aplicado à União, aos Estados, ao Distrito Federal e aos Municípios.

Brasília, 2011.

SILVA, C. A. T. TEIXEIRA, H. M.; NIYAMA, J. K. Evidenciação contábil em entidades desportivas: uma análise dos clubes de futebol brasileiros. In: Congresso USP de

Contabilidade, 9, 2009, São Paulo. Anais... IX Congresso USP de Contabilidade: São Paulo, 2009. CD-ROM.

SILVA, H. A. S.; ENSSLIN, S. R. Relação entre desempenho econômico-financeiro e evidenciação de indicadores de capital intelectual de natureza social e ambienta. RIGC. Vol. 10, pp. 1-19, 2012.

SILVA, J. A. F.; CARVALHO, F. A. A. Evidenciação e desempenho em organizações desportivas: um estudo empírico sobre clubes de futebol. Revista de Contabilidade e Organizações, Vol. 3, pp. 96-116, 2009.

SURROCA, J.; TRIBÓ, J.A. WADDOCK, S. Corporate responsibility and financial performance: The role of intangible resources. Strategic Management Journal. Vol. 31, pp. 463-490, 2010.

TUNG, N. H. (2001). Controladoria Financeira das Empresas: uma abordagem prática. $9^{a}$ ed. São Paulo: Universidade de São Paulo, 2001.

VIEIRA, F. S. Qualificação dos serviços farmacêuticos no Brasil: aspectos inconclusos da agenda do Sistema Único de Saúde. Rev. Panam. Salud Publica, Washington, vol. 24, 2008.

WANKE, P. F. Aspectos fundamentais da gestão de estoques na cadeia de suprimentos. Centro de Estudos Logísticos/UFRJ, 2003.

WANKE, P. F. Metodologia para gestão de estoques de peças de reposição: um estudo de caso em empresa brasileira. Revista Tecnologista. pp. 60-65, 2005. 